\title{
Implant dentistry to enter new era
}

\section{Nobel Biocare is inviting}

dental professionals to join the

MucointegrationTM era with the launch of

the Xeal and TiUltra surfaces.

Applied to not only implants but also abutments, these new surfaces were created to optimise tissue integration at every level for the purpose of improved implant treatment outcomes. Based on its decades-long expertise in applied anodisation technology, Nobel Biocare has understood that for optimal integration of dental implant restorations, different tissues demand different surfaces. While osseointegration is fundamental for the long-term function of implant restorations, soft-tissue integration is often overlooked. Dense soft-tissue contact with the abutment, however, can act as a barrier to protect the underlying bone.

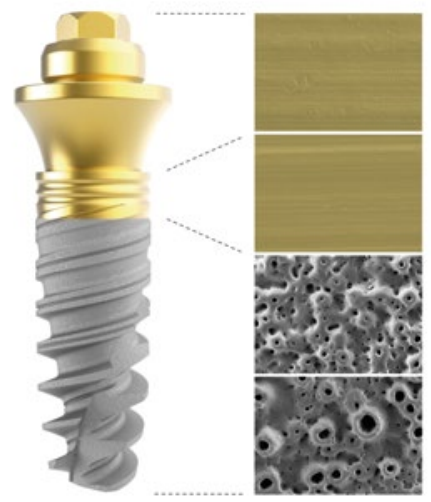

To maintain long-term tissue health and stability, surface chemistry as well as topography of the new Xeal abutment was specially designed to facilitate soft-tissue attachment to the abutment. Backed by data from a clinical study with two-years' followup, the Xeal surface has demonstrated a significant increase in soft-tissue height compared to machined abutment surfaces.

Developed with the ultimate goal of early osseointegration and long-term bone stability in mind, the ultra-hydrophilic, multi-zone implant surface, TiUltra, is taking anodisation technology a step further. Going beyond just roughness, the surface chemistry was optimised with the goal to positively influence its interaction with cells and ultimately osseointegration. TiUltra's topography has also been reimagined to gradually change from a minimally rough and non-porous collar to a moderately rough and porous implant apex thus respecting the natural transition from hard, dense cortical bone to cancellous bone. The TiUltra surface will be available with Nobel Biocare's NobelActive and NobelParallel Conical Connection implants. Combined with the Xeal abutment surface, dental professionals have a new complete solution for softtissue health, bone protection and fast osseointegration at their disposal.

For further information visit www. nobelbiocare.com/surface

\section{Sophisticated yet simple}

The product of 15 years of development, the TBR $\mathrm{Z1}$ is a highly adaptable implant, suitable for both anterior and posterior placement. It combines the flexibility and strength of a titanium screw with the aesthetic qualities, reduced bacterial colonisation and enhanced soft tissue integration of a zirconia collar.

Now available with either a $1.5 \mathrm{~mm}$ or $2.5 \mathrm{~mm}$ collar height, the Z1's unique design enables the implant to be submerged in order for excellent aesthetic results to be achieved - even in demanding circumstances.
The $\mathrm{Z} 1$ incorporates many advances but simplifies your workflow through its intelligently designed optimisations. Find out how much it can help you today.

For more information on the $\mathrm{Z} 1$ implant, visit tbr.dental, email support@denkauk. com or call 08007076212 .

\section{Set to steal the limelight}

\section{at the show}

See the latest Waterpik Water Flossing technology at the British Dental Conference and Dentistry Show 2019.

Waterpik will showcase a range of clinically proven products to help your patients to achieve and maintain superior oral health. The Waterpik team will be on hand to show you the various models and tips available and you can enjoy an interactive theatre experience and gain CPD.

The Waterpik Water Flosser is the gentle, safe and easy way to get your patient's flossing effectively, so come stand D40 and try it for yourself.

For more information on Waterpik visit www.waterpik.co.uk.

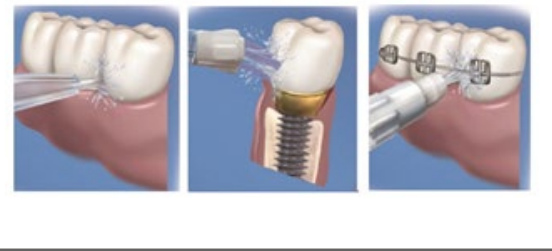

\section{New review}

\section{management system}

It's easy to feel afraid of reviews, especially if you see a negative one.

Designed specifically to help, Dental Design will launch its NEW review management system - EasyReview at the British Dental Conference and Dentistry Show, co-located with the Dental Technology Showcase.

Come along to the launch and hear our 15-minute talk repeated throughout both days of the show, with the dental marketing experts discussing how to deal with negative reviews.

Online reviews can improve your search engine ranking and boost your practice's internet presence, which is why you should always embrace - and never run from negative reviews.

Visit stand D4 to find out how.

To find out more about Dental Design's services, visit: https://dental-designproducts.co.uk/ email: enquiries@dentaldesign.co.uk or call 01202677277. 